Senecio canus Hook. - Silvery groundsel

Senecio integerrimus Nutt. var. integerrimus - Entire-leaved groundsel

Solidago canadensis L. var. gilvocanescens Rydb. - Canescent goldenrod

Solidago gigantea Ait. var. serotina (Ait.) Cronq. - Late goldenrod

Solidago missouriensis Nutt. - Low goldenrod

Solidago nemoralis Ait. var. Iongipetiolata (Mack. \& Bush) - Showy goldenrod

Solidago spathulata DC. var. neomexicana (Rydb.) Cronq. - Mountain goldenrod
Sonchus arvensis L. - Perennial sowhistle

Taraxacum officinale Weber - Common dandelion

Townsendia exscapa (Rich.) Porter Low townsendia

Tragopogon dubius Scop. - Yellow goat's-beard

*Voucher specimens in W.P. Fraser Herbarium collected by earlier investigators.

\title{
A SELECTED, ANNOTATED BIBLIOGRAPHY FOR SASKATCHEWAN BUTTERFLY WATCHERS
}

\section{BERNIE GOLLOP, 2202 York Avenue, Saskatoon, Saskatchewan. S7J 1J1}

The first part of this article (10 titles) is intended to help Saskatchewan butterfly watchers decide which identification guides will help them most to determine what butterflies they are seeing or catching. Most of these books also treat the ecology of each species, in varying detail. As with bird guides, the more butterfly books one has, the better the chance of identifying the more difficult species. The second part (five titles) deals with butterfly watching and biology in general. Prices are approximate and sometimes vary from store to store; all are available from the Blue Jay Bookshop.

Monarch

Gary Seib

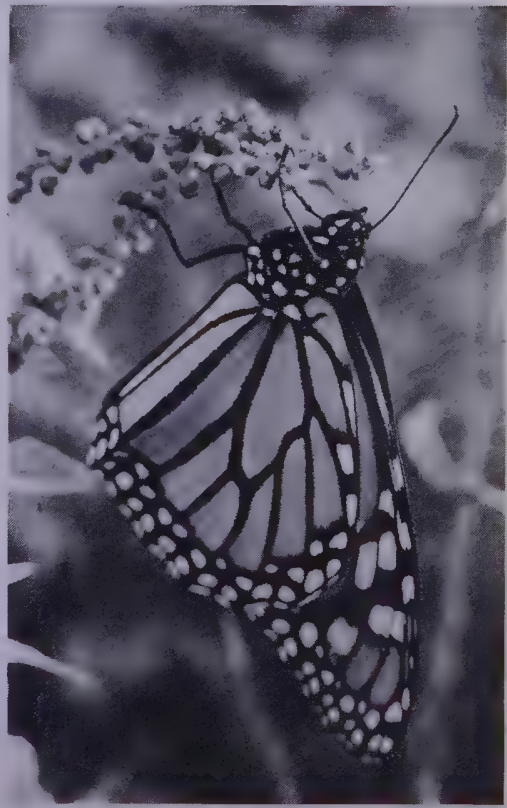


BUTTERFLIES OF SASKATCHEWAN - A

FIELD GUIDE. Ronald R. Hooper. 1973. Saskatchewan Museum of Natural History, Regina. 216 pp. (114 x $172 \mathrm{~mm})$ $\$ 3.75$.

This little unassuming publication illustrates pinned individuals of all species known to occur in the province at that time in 81 black and white plates; living specimens of 18 species are also shown in colour. Usually upper surfaces are shown for male and female and the under surface for one or the other (whole butterflies are illustrated). A useful feature of the book is the keys to identifying species. Each butterfly has a half page of text, facing the photographs, with paragraphs on appearance, range (incl. period found) and habits. This guide is complete, but lack of colour is a problem for some species.

Revised Checklist of Saskatchewan Butterflies. Ronald R. Hooper. September, 1986. Pages 154-163 in Vol. 44, No. 3 of Blue Jay (Saskatchewan Natural History Society).

Updated from the 1973 book, this article includes scientific and common names and geographical distributions for 144 species. This list has been used to evaluate how completely the identification guides below cover Saskatchewan species. [The author has prepared a fourpage summary of Hooper's paper, entitled "Seasonal and Geographical Distribution of Saskatchewan Butterflies" (1987). One line for each species presents a calendar showing the flight period, the common (English) name, in alphabetical order, provincial distribution and the pages for text and plate numbers in the Audubon field guide (reference below). Anyone wishing a copy may obtain it free by sending me a stamped self-addressed envelope.]

The sequence of the guides below is in order of their completeness in illustrating Saskatchewan species, particularly in colour.
THE BUTTERFLIES OF NORTH AMERICA. A NATURAL HISTORY AND FIELD GUIDE. J. A. Scott. 1986. Stanford University Press, Stanford, CA. 583 pp. (200 $\times 259 \mathrm{~mm}$ ) $\$ 65.00$.

This volume begins with a 110 -page section on biology and ecology, followed by keys for identifying eggs, larvae, pupae and adults to family, in most cases. All 679 species of North American butterflies (north of Mexico) are shown in more than 1800 photos of pinned specimens (half butterflies) in 42 plates. Up to 12 pictures are given for a species and its subspecies. An additional 22 plates depict living butterflies and their immature stages. The arrangement is basically by colour and pattern. The underside is always shown and the upperside usually. There are from $1 / 4$ to 2 pages of text per species which cover habitat, larval host plants, eggs, larvae, pupae and life history of the adult. A map shows province/state distribution and a Saskatchewan list can be built up from the maps. Appendices include studying butterflies, a brief bibliography, glossary, indices to host plants and butterflies. Unfortunately, practically all of the illustrations are identified by scientific name only. While it may be too bulky as a field guide, this is the best handbook currently available. All Saskatchewan species are shown in colour, but not all subspecies.

AUDUBON FIELD GUIDE TO NORTH AMERICAN BUTTERFLIES. R. M. Pyle. 1981. Knopf, New York. 924 pp. (102 x $195 \mathrm{~mm}) \$ 20.50$.

There are 707 plates (three per page) of living butterflies. The book is organized taxonomically which, while it puts the somewhat similar members of a family together, does not group species of similar colour. There is a single plate for each of almost $2 / 3$ of the Saskatchewan species, but most of these include two photos, showing upper-and underwing. Because the pictures are of living insects, the angle and details are not always the best. There is almost a page of text per species with paragraphs 
on description, similar species, life cycle, flight (period), habitat, range and remarks. One hundred thirty-five Saskatchewan species are shown in colour; six are shown only in black-and-white and three are discussed but not illustrated. (The black-and-whites are: Persius Dusky-wing, Freija's Fritillary, Northern Marble-wing, Plains Gray and Orange Roadside skippers and Great Northern Sulphur. The three are: Afranius Dusky-wing, Oslar's Roadside Skipper and Kahli Swallowtail.)

BUTTERFLIES OF MANITOBA. Paul Klassen, A.R. Westwood, W.B. Preston and W.B. McKillop. 1989. Manitoba Museum of Man and Nature, Winnipeg. 290 pp. $(204 \times 254 \mathrm{~mm}) \$ 21.95$.

All 144 kinds of Manitoba butterflies are illustrated with colour photographs of pinned specimens (whole butterflies). The images are larger than in other books and there are up to seven for a species. There is about a page of text for each species dealing with description, similar species, life cycle, habitat, range, Manitoba records, subspecies and remarks; a provincial distribution map is included. Appendices cover collecting techniques and guidelines, index of food plants, checklist, location of collection sites and flight periods of each species. A five-page list of references and a glossary is included. A useful feature of this volume is the listing of alternate scientific names for species, often necessary for finding a species in another book. Two major drawbacks are that the plates are identified by and the butterfly index is given in scientific names only. Twenty-nine Saskatchewan butterflies are not illustrated. (Of the species not illustrated in the Audubon guide, only Kahli's Swallowtail is shown here - male and female, ventral and dorsal.)

FIELD GUIDE TO WESTERN BUTTERFLIES. (\#33 in the Peterson Field Guide Series) J. W. Tilden and A. C. Smith. 1986. Houghton Mifflin, Boston. 370 pp. $(114 \times 182 \mathrm{~mm}) \$ 22.95$.
Photographs are of pinned specimens in 48 plates (half in colour), usually upper and lower surfaces of wings (half butterflies). Arrows on the illustrations point to distinctive field marks - a definite advantage. Text is usually $1 / 3$ to $1 / 2$ page with headings for identification, early stages, food, adults (dates), range, habitat, subspecies and remarks. Included are a glossary, bibliographies on various subjects, directories of supply houses and organizations with their publications and indices to host plants and butterflies, in English and scientific names. Six Saskatchewan species are not pictured and only half of those illustrated are in colour. (Missing are Harris' Checkerspot, Edward's and Red-banded hairstreaks, Least and Labrador skippers, and Kahli Swallowtail.) (Afranius Duskywing and Oslar's Roadside Skipper, not illustrated in the Audubon Guide, are shown here in black-and-white.)

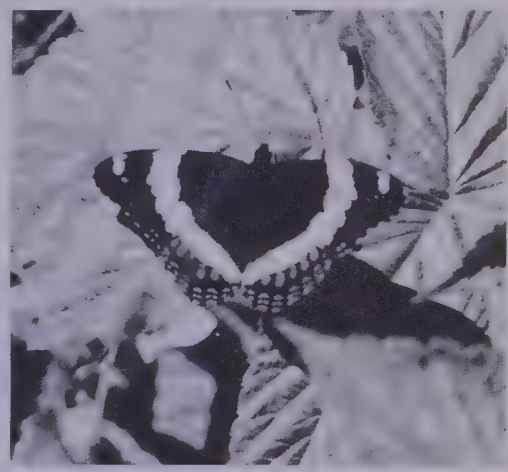

White Admiral

Bernie Gollop

FIELD GUIDE TO THE BUTTERFLIES OF NORTH AMERICA, EAST OF THE ROCKIES. (\#4 in the Peterson Field Guide Series) A. B. Klots. 1951. Houghton Mifflin, Boston. 349 pp. (121 x 192 mm) $\$ 19.95$.

A mixture of black-and-white photos and coloured paintings of pinned specimens (upper and lower views in most cases) in 34 plates. Arrows point out field marks. Species text deals with description, similar species, larva, food, flight period, range and subspecies. Chapters 
cover collecting and preserving, the butterfly's environment, life histories and growth, adult butterfly, classification, indices to host plants and butterflies. Fiftyeight Saskatchewan species are not pictured.

BUTTERFLIES AND MOTHS. R. T. Mitchell and H. S. Zim. 1987 Revised. Golden Press, New York. 160 pp. (102 x 153 mm) $\$ 4.95$.

Butterflies occupy the first 80 pages of this volume of the Golden Nature Guides. Paintings of natural poses more often show male and female, less often upper-and undersides, and seldom both aspects of both sexes. Some species have only a single image. Text is sparse. Most species have range maps and some illustrations of larvae and pupae. The arrangement is taxonomic. Sixty-three of Saskatchewan's 144 species are not illustrated.

AN INSTANT GUIDE TO BUTTERFLIES. Pamela Forey and Cecilia Fitzsimons. 1987. Bonanza Books, New York. 124 pp. $(106 \times 178 \mathrm{~mm}) \$ 12.00$.

Paintings show adults in natural poses, often with caterpillars. However, the presentation is uneven - sometimes only one image, sometimes two (male and female or upper and lower), some- times three. The organization is by colour, which is an advantage. There is one page per species, the text covering description, larvae and food plants, ecology and similar species. A map shows distribution by 10 regions for North America; Saskatchewan and Manitoba are combined into one region. There are no scientific names and some of the English names appear to be unique. Sixtyeight Saskatchewan species are not shown.

\section{BUTTERFLIES OF NORTH DAKOTA; AN} ATLAS AND GUIDE. A. A. Royer. 1988. Science Monograph 1, Division of Science, Minot State University, Minot, ND. 192 pp. \$19.00. Not seen.

The following two out-of-print books are particularly useful, although the lack of English names and the use of often outdated scientific names causes problems.

BUTTERFLIES OF NORTH AMERICA. W. H. Howe. 1975. Doubleday, Garden City, NY. 633 pp. (187 x $267 \mathrm{~mm})$

There are 2093 paintings of pinned specimens in 97 plates. (A painting usually consists of an upper and lower view of half butterflies.) The organization is taxonomic with much attention to subspecies. As a result, there are up to 26

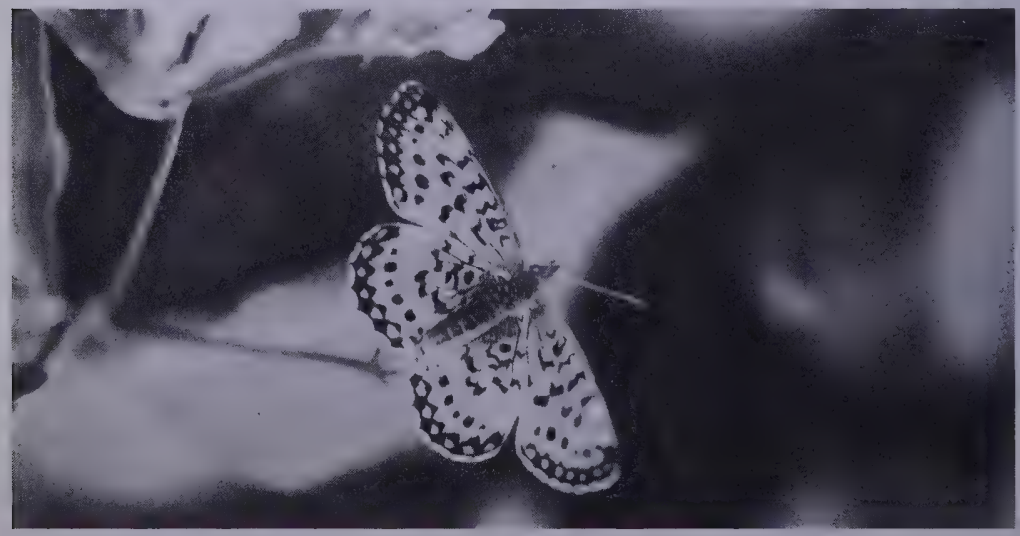


paintings of one species. Seventy-four pages are devoted to ecology and collecting. There are a glossary, bibliography, indices to host plants and butterflies. All Saskatchewan species are shown and in only four cases the appropriate subspecies is not illustrated (although they are discussed) - Acmon Blue, American Copper, Acadian \& Gray hairstreaks.

HOW TO KNOW THE BUTTERFLIES. P. R. and A. H. Ehrlich. 1961. W. C. Brown, Dubuque, lowa. 262 pp. $(150 \times 218 \mathrm{~mm})$

This is one of at least 33 volumes in the Pictured-Key Nature Series. It is a book of dichotomous keys - keys that offer two choices in each of a series of steps; whichever alternative fits the butterfly in one step determines which step will come next - without colour, although the aspect of each species critical to identification is usually drawn. Skippers (incl. Dash, Dusky- and Cloudywings) are not included. Otherwise all Saskatchewan species are keyed out except for two that were apparently not recognized as species when the book was written - Kahli Swallowtail and Western White.
NATURAL HISTORY

THE AUDUBON SOCIETY HANDBOOK FOR BUTTERFLY WATCHERS (A guide to observing, locating, identifying, studying and photographing butterflies). R. M. Pyle. 1984. Scribner's, New York. 274 pp. $(200 \times 260 \mathrm{~mm}) \$ 26.95$.

Among its 19 chapters are: Why watch butterflies/ About butterflies/ Butterfly watching equipment/ Counting butterflies/ Butterfly behaviour/ Butterfly gardening/ Rearing butterflies/ Butterfly photography/ Great North American butterfly spots. An excellent survey for the butterfly hobbyist.

THE NATURAL HISTORY OF BUTTERFLIES. John Feltwell. 1986. Croom Helm, London. 133 pp. (164 x $242 \mathrm{~mm}) \$ 27.00$.

Chapters discuss fossils and butterfly hunters, structure and function, life cycles, food plants, coloration and camouflage, habitats, butterflies and sunshine, populations and territories, migration and conservation. Examples are drawn from the butterflies of Europe and its American visitors.

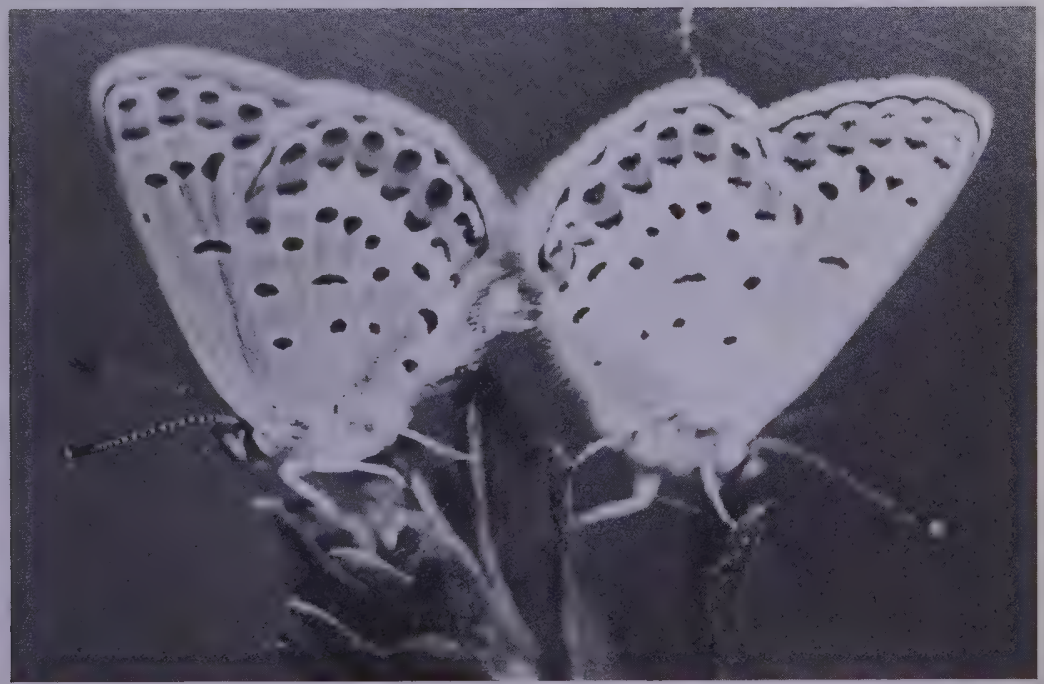


BUTTERFLY AND MOTH. (Eyewitness Books) Paul Whalley. 1988. Stoddart, Toronto. 64 pp. $(225 \times 288 \mathrm{~mm}) \$ 14.95$.

Profusely illustrated with photos and paintings in colour, this book gives a brief, basic understanding of butterfly life history. It devotes two pages of pictures and text to each of such topics as courtship and egg laying, emerging caterpillar, caterpillar to pupa, pupa stage, emerging butterfly, migration and hibernation, camouflage, mimicry, endangered species, etc., based on examples from around the world.

THE LIVES OF BUTTERFLIES. M.M. Douglas. 1986. University of Michigan Press, Ann Arbor. 241 pp. (151 x $236 \mathrm{~mm})$.
A book for the "interested reader and professional." Chapters deal with evolution, immature stages and adults, communities, migration, parasites, predators, mating, host plants. A 7-page glossary, 18-page bibliography and an index conclude the volume.

THE YEAR OF THE BUTTERFLY. George Ordish. 1975. Scribner's, New York. 147 pp.

A fictionalized account of two monarch butterflies beginning as newly hatched caterpillars and following them from August through July. It is based on the great body of scientific research done on this species.

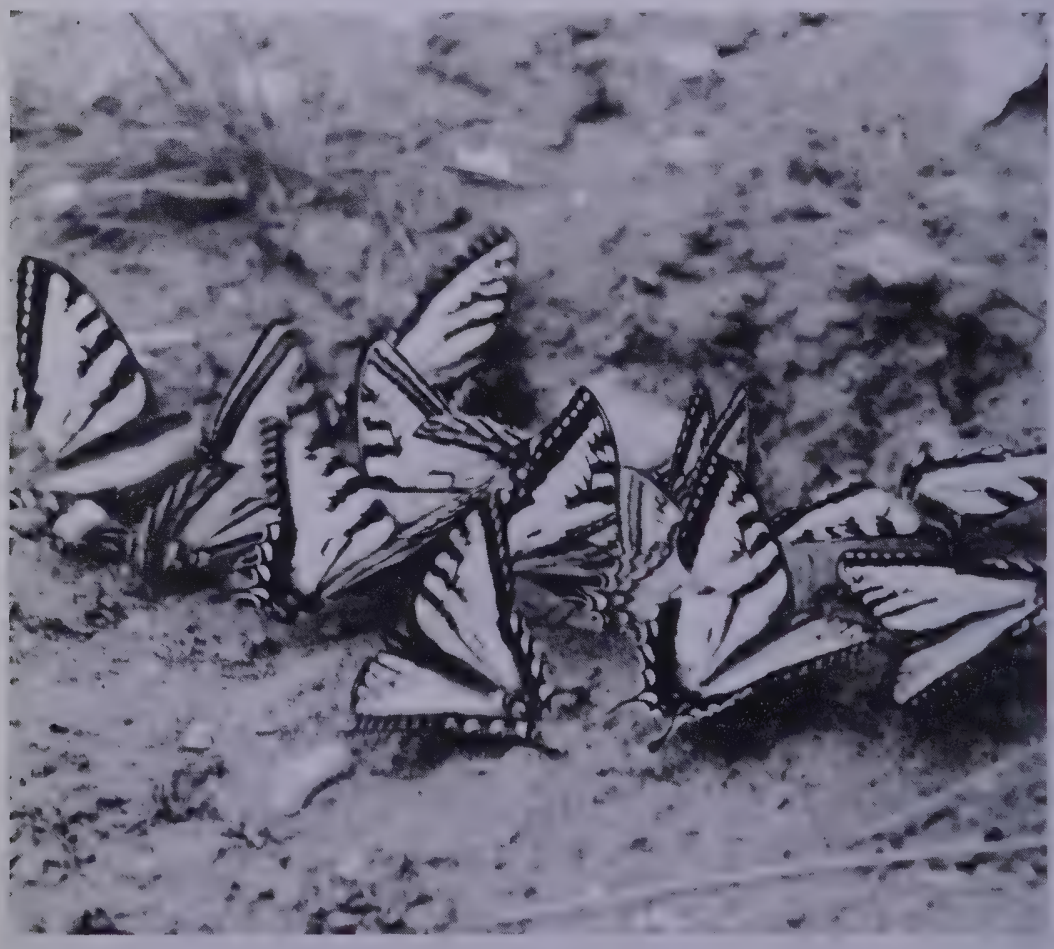

Tiger Swallowtails

Larry Morgotch 